\title{
Translation Strategies of The Strange Days Under Skopos Theory
}

\author{
Yumin Gong \\ Shanxi Normal University, Linfen, China
}

\begin{abstract}
Sven Birkerts (1951-) is an American essayist. His essay The Strange Days is well received by readers. In the context of globalization, literary translation is an important part of cultural exchanges. The Skopos Theory is the theory that applies the Skopos concept to translation. The core concept of Skopos Theory is that translation strategies and methods are determined by the purpose of translation. In the process of translation, the translator should follow three principles, namely, skopos rule, coherence rule and fidelity rule. The translation of literary texts coincides with the idea of Skopos Theory. This paper analyzes the advantages of Skopos Theory in the selection of translation strategies for the translation of The Strange Days from the perspective of the principle of skopos, coherence and fidelity.
\end{abstract}

Index Terms-The Strange Days, Skopos Theory, translation strategy

\section{INTRODUCTION}

Since the 20th century, the world has entered the era of globalization, including politics, economy and culture. Under the high demand of the market, various translation forms emerge as the times require. At the cultural level, it is concentrated in the translation of literary works, which is conducive to the communication and dissemination of different cultures between countries. The Strange Days wrote by American essayist Sven Birkerts. Sven Birkerts (born September 21, 1951) is an American essayist and literary critic of Latvian ancestry. He is best known for his book The Gutenberg Elegies, which posits a decline in reading due to the overwhelming advances of the Internet and other technologies of the "electronic culture." Birkerts was born in Pontiac, Michigan. He graduated from Cranbrook School and then from the University of Michigan in 1973. Birkerts is a Director of the Bennington College Writing Seminars and an editor of AGNI, the literary journal. He taught writing at Harvard University, Emerson College, Amherst College, and Mount Holyoke College. He lives in Arlington, Massachusetts with his wife Lynn. He has two children, Mara and Liam. His father is noted as an architect Gunnar Birkerts.

The paper mainly narrates that the author's experience of feeling strange while witnessing the time after surgery passes by and thinking of having a daydream. The text includes six parts: at the beginning author introduced changes of life after surgery, then explained the reason why the operation was conducted; through describing the preceding imagination before whole surgery, and the anesthesia during the operation as well as physical sensation after it faded away, the author recorded how to spend the time during the convalescence, from mornings, afternoons to nights, and at last wrote the feeling of recovering. The translation project chooses Sven Birkerts's The Strange Days as source text. As for the translation, there is no translated version and it's the first time to do it.

\section{THEORETICAL FRAMEWORK}

In this part, the paper adopts the Skopos Theory as the theoretical framework where a brief introduction to Skopos Theory is presented and the three principles of Skopos Theory are introduced afterwards.

\section{A. A Brief Introduction to Skopos Theory}

Compared to other translation theories such as Relevance Theory, the Skopos Theory has been extensively applied in translation studies. Since translation studies are purpose-oriented and this paper concerns literature translation whose intention is to accurately convey the original author's meaning to target readers, this paper draws on Skopos Theory as the theoretical framework beginning with definitions and development as the brief introduction and the three principles of Skopos Theory is presented subsequently.

The Skopos Theory is a concept in translation studies which is affiliated to functional theories of translation. Skopos comes from Greek word meaning "aim" or "purpose." The 1970s saw a move away from equivalence theory to functional theory as more scholars thought the current translation could not answer the needs of practice. Such a shift indicates that the translation theory has come to notice the functional and sociocultural aspects of translation theories (Li, 2005). In the 1970s, Skopos Theory made its appearance in translation theory and was presented by a German linguist Hans J. Vermeer (Munday, 2016). This theory requires that translators should carefully consider the purpose of source text and the target text before their translation.

The Skopos Theory, as a branch of functional theory, has undergone four phases during its development. Firstly, Katharina Reiss established the functionalism through her Text Typology Theory by incorporating Buhler's theory. Reiss (c) 2020 ACADEMY PUBLICATION 
made a distinction between these text types which were informative text, expressive text and operative text. The informative text mainly deals with contents like illustrating facts whereas the expressive text chiefly focuses on aesthetics. The angel is dialogic which aims at making appeal to target receiver. From this point of view, it can be seen that this kind of text type concerns conveying source text's function to the target receivers thus arousing corresponding reactions. Secondly, Vermeer, who is Reiss's student, further developed translation theory based on the teachers study and reckoned that translation is an aim-oriented action, which means that the "skopos" dominated the translation action. Vermeer held that any kind of translation may be considered as an action with an aim or a purpose. As translation involves human communicational activities in the process of translation, the purpose, as the theory denotes, is the core element(Vermeer, 1989). Thirdly, another scholar Justa Holz Manttari majoring in translation studies enhanced functional theory with a belief that translation action was about producing a message transmitter which was intended to be applied in super-ordinate action systems (Nord, 2001). For example, translation means language transformation whereas the message transmitter encompasses text with images, sounds and body languages that belong to nonverbal elements. Last, Christiane Nord is another academic who again furthered this theory and focused on text analysis in the book Text Analysis in Translation where Nord made a clear distinction between two basic types: documentary translation and instrumental translation (Nord, 2005).

From above developments, it is clear that Skopos Theory has gone through significant changes to continuously evolve in translation studies and this theory has moved to consider cultural aspects of translation and intended to convey target outcome by the translator.

\section{B. Three Principles of Skopos Theory}

As we have mentioned above, skopos emerged in 1970s. And its emergence has shifted translation studies into functional theory rather than static linguistic typologies of translation. At the same time, a functionalist and communicative approach to the analysis of translation has been proposed, in Germany. According to Vermeer, the skopos states "one must translate, consciously and consistently, in accordance with some principle respecting the target text. The theory does not state what the principle is: this must be decided separately in each specific case." (Vermeer,1989, p.182). He regards translation as a kind of human action which has a certain aim and purpose, for he holds such a firm belief that any action has an aim and purpose, without an exception of translation activity which is based on the source text. Moreover, an action can generate a possible result, a kind of new situation or new event, probably something new. Translation is considered as a purposeful action.

Then, based on Skopos theory, how does a translator reproduce a satisfying work? Firstly, he should consider the initiator's requirement of the purpose of the translation. That is to say, the translator should adequately acquaint with client's translation brief, which includes: the prospective text functions the initiator and the recipient; when and where to receive the text; the medium of transmitting the text; and the motivation of writing and translating the original text. (Nord, 2001).This information gives a clue for the translator to establish a rational arrangement for the information included in the target text. Being familiar with the translation brief, the translator could have a clear image of how to work at his translating job, what kind of translation strategies he will take, and what types of translation he'd better to use. Here comes a very important question for translating. What principles should the translator adopt to guide his translation?

Certainly, Vermeer had concerned this problem at that time. In the light of his researches, in 1978, he first formulated his Skopos theory, putting forward three rules in his paper Framework for a General Translation Theory to confine the translator's translation decision. Then the rules of Skopos theory were gradually grown into the foundation for a general theory of translation in the book Groundwork for a General Theory of Translation (1984) written by Reiss and Vermeer together. They explained the basic rules as follows: (qtd. in Jeremy Munday, 2001)

1) A translatum (or target text) is determined by its skopos.

2) A TT is an offer of information (Informationsangebot) in a target culture and target language concerning an offer of information in a source culture and source language.

3) A TT does not initiate an offer of information in a clearly reversible way.

4) A TT must be internally coherent.

5) A TT must be coherent with the SL

6) The five rules above stand in hierarchical order, with the skopos rule predominating.

In short, the above rules actually characterize three basic rules, they are: skopos rule, coherence rule, and fidelity rule.

1. Skopos Rule

The Skopos rule is paramount (Munday, 2016). Since the whole translation action is determined by its translation purpose, the Skopos rule indicates that the literary translation should aim at the purpose of accurately conveying author's meanings to target readers. Vermeer once categorized translation purpose into three types: the general purpose which means that the translator could make a living by translation work; the communicative purpose which means that through the translation the translator might educate the reader or target audiences; the purpose of a translation method or procedure.

Skopos theory claims that "skopos rule" is the most important principle. Therefore, the translator should have a clear-cut purpose and decide what kind or kinds of translation methods or strategies should be adopted under this 
purpose - conservation translation strategy, substitution translation strategy or the combination of the two. Literal translation plays a critical role in cultural communication. Under the guidance of the skopos rule, literary translators usually do the translation with the established purpose. Usually, literary works are also translated for a given purpose. Skopos rule will help readers to find what kind of purpose the translator tries to achieve. Skopos rule illustrates that translation always has a certain purpose. The purpose of this rule can help us break through the dilemmas between dynamic equivalence and formal equivalence. Skopos theory can also be used to dispel some disagreements. For example, there are some controversial issues between free translation and literal translation. It cannot be solved until the appearance of the skopos theory. "Free" or "faithful" is decided by the purpose that the translation is expected to achieve. This rule indicates that whether literal or free translation or other translation methods the translator may adopt all methods which should be decided by the purpose of the translation namely to meet the needs of the translation purpose.

2. Coherence Rule

Different from the skopos rule, coherence rule lays stress on intra-textual coherence. The source text and target text should comply with intra-textual coherence rule. The target text should be acceptable and meaningful in a sense that it is coherent with the situation in which it is received. It means to be faithful to the target text. In other words, the translated works should be coherent, especially for the target text receivers in consideration of their circumstances and knowledge. Intra-textual coherence is easy to understand. It means the target texts not only can be read but also can be accepted. Under this rule, the receiver is the most important role. According to different situations, the translator needs to choose the most appropriate translation methods. In this way, the receiver could have a good understanding of the target text. For translators, it is important to make sure that the translated works are meaningful to the target language receivers.

The coherence rule means that, as Reiss and Vermeer (1984:113) said, intratextual coherence should be acceptable in a way that it could be coherent in the receivers' situation. Munday (2016:128) stated that the translation must be translated in a way that should be interpretable and acceptable for target audiences regardless of their cultural backgrounds, knowledge, and needs. To put it simple, coherence rule requires the translation should be understood by the target audiences, namely to meet the purpose of its intended expectation, and then the translation is adequate and successful.

\section{Fidelity Rule}

Nord puts forward the fidelity rule. According to Nord, there are some shortcomings of the skopos theory. Therefore, he sets forth fidelity rule to reduce cultural differences as much as possible. In Nord's idea, the translator has the moral responsibility for the translation recipient. The fidelity rule refers to the inter-textual coherence between the original text and the translated. Another aspect of this principle is the translator should be loyal to the source text. Translators should respect the writers and readers. When translators translate literary works, they should make some adjustments to the target texts according to writer's needs. Skopos rule is the priority to comply. The fidelity rule is inferior to the other two standards. Nord takes fidelity rule as a supplement. Translators cannot compel their readers to accept their views. Translation is a process of transmitting information from the source text to the target text. The target text must conform with source text in the aspect of content, namely, being faithful to the source text. However, the consistency between source text and target text is usually decided by the translator and the purpose of the translation.

The fidelity rule means that, as Munday (2016:127) said, the target text should be intertextual coherence with the source text. To some extent, intertextual coherence shows that the relationship between the target text and the source text should be faithful in a maximal way. It should be pointed out that faithfulness in this rule does not mean that the translation should be the imitation of the source text. In contrast, faithfulness means that the translator may adjust the faithfulness degree to achieve the target faithfulness.

To sum up, these three rules are associated with each other but in a diverse hierarchical order. Munday (2016:128) claimed that the intertextual coherence, namely the fidelity rule, is of less importance than intratextual coherence within the target text, namely the coherence rule. Besides, the two rules are then subordinate to the skopos rule which means that the skopos rule predominates among coherence rule and fidelity rule. Sometimes, to achieve the expected purpose of the translation, the translator should make sure that the skopos rule is firstly met and then ensure that the translation text is coherent intratextually, and finally be sure that the translation is coherent with the source text intertextually. The three important rules are significantly practical in translation fields. The importance of these three rules is not equal, and there is a relation of subordination among them. Coherence rule and fidelity rule are subordinate to skopos rule. Fidelity rule is subordinate to coherence rule. The choice of translation strategies is influenced by many factors, such as social background, sensitivity or world knowledge, expectations and communicative needs. As one of the most symbolic translation theory in the functional school, skopos theory emphasizes the fact that translators should choose translation strategies according to their needs and purpose.

\section{Translation Methods of the Strange Days under Skopos Theory}

In order to possess a readable target text, the translator chose three methods under the skopos theory: literal translation, free translation and adaption.

\section{A. Literal Translation}


Generally, literal translation refers to the translation that a translator tries to keep the original form and meaning, including meaning, structure, style, figure of speech, etc (Newmark, 2006). But it is not the word-for-word translation. So when the translator finds that writing structure and expressing means of English are identical to Chinese, employing literal translation. Let us look at some examples in source text.

Example 8: Extra pillows 外加的枕头

Example 9: Bottle of water 水瓶

Example 10: Things have gotten quiet these days, in a way they haven't for a long time.

这些天周围事物变得一片寂静, 已经很久没有这种状态了。

Example 11: Convalescence-means exactly what? I look it up. Con- + valescere: “altogether grow strong." Everything hurt, I heard myself crackling like wicker with every movement I made. I was going up the stairs on all fours, like a dog.

恢复期-真正的含义是什么? 我查了字典。Con- + valescere: 全身强壮。浑身疼痛, 每次移动我都听到自己发 出像柳条一样的爆裂声, 用四肢上楼梯, 样子看起来像一条狗。

Example 12: Everything was explained to me. I was told, step by step, what would happen. But the experience - from the morning of my going in for the surgery on - has been nothing like what I had come to imagine.

他们向我说明了每件事。告诉我一步一步要进行的事项。但是从我早晨进入手术室, 所经历的和之前所想完 全不同。(literal translation)

每件事都被解释给我听。我被告知一步一步会发生什么。但是那个经历, 从早晨进入手术室, 之前所想完全 不同。(word-for-word translation)

These examples are very vivid and figurative. They are good examples for literal translation. Because there are similarities between two languages and cultures, it is realizable to apply literal translation.

\section{B. Free Translation}

Free translation is that a translator roughly expresses the original meaning, keeping the target language smoothly (Nida, 1993, p.31). But it is not the random translation. When English expression is not conformable to Chinese, free translation can be used to flexibly translate.

Example 13: Answer glibly in the moment 不假思索对答如流

Example 14: ...extended moments - because those are what I have now, day after day, the succession of them marking the path back to being fully mobile, fully able, but on the way I have these near silences

被拉长的瞬间-这样的瞬间总是环绕着我, 日复一日, 而这些瞬间标志着我可以回到活动自如、无所不能的状 态，但是这个过程几乎是寂静的

Example 15: Gain health—simple enough. I am gaining back my health after a surgery, the right hip replaced, because finally there could be no more waiting.

简而言之就是获得健康。因为右臀手术到最后不能再拖了，所以手术后我在恢复。

Example 16: It was time.

得做手术了。

Example 17: They introduce a set of new variations into the old picture.

他们在我身体注入了新的变化。

\section{Adaption}

Owing to the different styles and manners of English and Chinese writing as well as culture between them are different, the translator needs to adapt some words, sentences and cultural knowledge so as to bring forth a readable and coherent translated text(He \&Tang, 2007).

Firstly, it is necessary for us to convert some word classes into a certain word class in translation.

Example 18: implanting of a titanium

$$
\text { 注入钛板 }
$$

The noun "implanting" derived from verb "implant" here is converted into Chinese verb

Example 19: It was not dread of the surgery.

$$
\text { 不是害怕手术 }
$$

The adjective "dread" indicating one's feeling, here is converted into Chinese verb

Secondly, the passive voice in English is much more often used than in Chinese, therefore sometimes it is necessary to convert the passive-voice English into the active-voice Chinese.

Example 20: Everything was explained to me.

他们向我说明了每件事。

“他们”is added as the subject of the active-voice Chinese in the translation.

Example 21: I began to realize what was involved

我开始意识到会发生什么事

Thirdly, language is part of culture, some expressions in source language can be translated certain idioms in target 
text.

Example 22: beyond what had been described

无法言表

Example 23: day after day

日复一日

\section{CONCLUSION}

Skopos theory, unlike the traditional translation theories that only perceive the source text as an information provider, regards translation as a cross-cultural communication activity with the specific purpose. Skopos theory allows the translator to choose information intentionally to achieve the goal of rendering and meet the needs of the target language reader. Fulfilling the mission of translation is the fundamental principle of Skopos theory. Under the guidance of the skopos theory, translator uses some translation methods including literal translation, free translation and adaption. Through this translation, author gained some enlightenment of translation mainly as follows:

Firstly, understanding the original is the first thing to do in translating. In this procedure, it requires us to understand the original thoroughly and fully as possible as we can. At the same time, it will be done through the context, and the original will be read at least three times or more. At the first time roughly read the original to understand the general meaning and mark some places new or difficult to us. At the second time carefully read the original to solve the difficult points, and if in necessary, read it paragraph by paragraph, sentence by sentence, and even word by word. The third time thoroughly read the entire passage to completely understand it. Secondly, the translator needs to strengthen the cultivation of Chinese. In addition to learning English well, it is also important to properly use Chinese. No matter how excellently we master English, we can not produce a good translation without solid Chinese foundation. Thirdly, we should learn from other outstanding translation versions and obtain much inspiration in this process of translation. Fourthly, after finishing translating, the translator has to proofread the translation and examine whether some paragraphs, sentences, clauses, and word, etc. are left out. Check out whether some grammatical or speaking errors in the translation. Reading the version several times to see whether it is smooth, fluent, harmonious, and wordy or not.

\section{REFERENCES}

[1] Bian, J. (2008). Study on Functionalist Skopos Theory of Translation. Beijing: China social science press.

[2] Feng, Q. (1997). A Practical Coursebook on Translation. Shanghai: Shanghai Foreign Language Education Press.

[3] He, S. \& G. Tang. (2007). A Practical Course in English-Chinese Translation. Nanjing: Southeast University Press.

[4] Li, H. (2005). Methodology of Western Translation Studies: since the 1970s. Beijing: Peking University Press.

[5] Munday, J. (2016). Introducing Translation Studies. London: Routledge.

[6] Newmark, P. (2001). A Textbook of Translation. Shanghai: Shanghai Foreign Language Education Press.

[7] Newmark, P. (2006). About Translation. Beijing: Foreign Language Teaching and Research Press.

[8] Nida, E. (1993). Language, Culture, and Translation. Shanghai: Shanghai Foreign Language Education Press.

[9] Nord, C. (2001). Translating as a Purposeful Activity: Functionalist Approaches Explained. Shanghai: Shanghai Foreign Language Education Press.

[10] Nord, C. (2005). Text analysis in translation: Theory, methodology, and didactic application of a model for translation-oriented text analysis. Amsterdam: Rodopi.

[11] Reiss, K. \& H. Vermeer. (1984). Groundwork for a general theory of translation. Tubingen: Niemeyer.

[12] Zhang, P. \& Y. Yu. (1980). A Course in English-Chinese Translation. Shanghai: Shanghai Foreign Language Education Press.

Yumin Gong was born in Taiyuan, China in 1994. She received her bachelor degree in translation from Tianjin University of Commerce Boustead College, China in 2017.

She is currently a master degree candidate in the School of Foreign Language, Shanxi Normal University, Linfen, China. Her research interests include pragmatics and translation. 